\title{
Correction to: Emerging Technologies During the Era of COVID-19 Pandemic
}

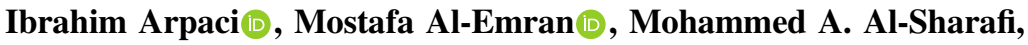 \\ and Gonçalo Marques
}

\section{Correction to:}

I. Arpaci et al. (eds.), Emerging Technologies During the Era of COVID-19 Pandemic, Studies in Systems, Decision and Control 348, https://doi.org/10.1007/978-3-030-67716-9

This book was inadvertently published with the incorrect affiliation of the editor "Gonçalo Marques" has been corrected as in below:

Polytechnic of Coimbra, ESTGOH, Rua General Santos Costa, 3400-124 Oliveira do Hospital, Portugal. 